\title{
Can seed production and restricted dispersal limit recruitment in Pinus pinaster Aiton from the Spanish Northern Plateau?
}

\author{
Libertad Juez Santiago C. González-Martínez, Nikos Nanos, Ana I. de-Lucas, Cristóbal Ordóñez, Carlos del \\ Peso, Felipe Bravo
}

\begin{abstract}
A B S T R A C T
Natural regeneration faces increasing difficulties in dry forests from the Mediterranean basin, including for normally well-regenerating species such as maritime pine (Pinus pinaster Aiton). In this paper, we studied female fertility, seed dispersal and spread rates in P. pinaster from the Spanish Northern Plateau, where natural regeneration failure is a main concern for forest managers. For this purpose we periodically collected data from seed traps and trees located at two core locations across several years. We found sig-nificant variation in interannual cone production, with the best seed trees being the same across years. In addition, we found highly skewed distributions of female reproductive effort and large fertility differ-ences across stands located few kilometres away. Annual seed dispersal kernels fitted lognormal or 2Dt models depending on the stand analysed, with median dispersal distances between 14 and $25 \mathrm{~m}$. Kernels fitted for maximum dispersal periods showed an outstanding intraseasonal variation of median dispersal distances, from 10 to $54 \mathrm{~m}$, in association to variable patterns of rainfall and maximum wind speed. The amount of seed produced appeared to be enough to guarantee the natural regeneration of the stands during the typical 20 -year regeneration period. Colonisation simulations concluded that Med-iterranean maritime pine has a notable dispersion capacity, which is strongly influenced by levels of fecundity and, especially, by the number and frequency of long-distance dispersal events. The latter play a key role in tree dispersion processes through enlarging the occupied area and fostering the invasion of abandoned crop land.
\end{abstract}

Mating system Seed rain Dispersal kernel Dispersion Sortie-ND Mediterranean region

\section{Introduction}

The regeneration phase is a key part of sustainable forest management, as it determines the feasibility of most silvicultural treatments and the quality of the goods and services provided by the forest (Gordo et al., 2012). It also conditions the future development of the stand. Therefore, understanding natural regeneration processes of plant species is an important prerequisite for their conservation and management (Guarigata and Pinard, 1998). Stand regeneration is a complex process driven by the interplay of multiple abiotic and biotic factors (Tiscar Oliver, 2007), involving different stages in the life cycle of plants. The success of each one, with the seed and seedling stages recognised as the most important
(Houle, 1996), depends in turn on the interactions of many site factors (Kitajima and Fenner, 2000).

Seed dispersal is one of the central processes in the dynamics and evolution of plant populations (Ouborg et al., 1999), operating at multiple temporal and spatial scales (Nathan, 2001). In plant populations, seed dispersal is the predominant stage at which plants move in space (Schupp and Fuentes, 1995; Nathan and Muller-Landau, 2000), generating the initial spatial pattern of new individuals. Besides, the process has tremendously important implications at multiple scales of organisation: for the survival, growth and reproduction of individuals; for the composition, structure and dynamics of populations and communities; and for the persistence, evolution and geographical distribution of species (Nathan, 2001). Thus, spatiotemporal patterns generated during the seed stage are critically important to plant dynamics (Nathan et al., 2001; Nathan and Muller-Landau, 2000; Schupp and Fuentes, 1995), in particular long-distance dispersal (Nathan et al., 2002; Nathan and Muller-Landau, 2000). As a result, a more realistic incorporation of seed dispersal in forest dynamic models is needed 
(Nathan et al., 2001). However, models of tree spread have rarely been implemented for pines (Prévosto et al., 2003; Lavi et al., 2005), and very few deal with Pinus pinaster (Higgins et al., 2001; Thuiller et al., 2005).

Maritime or cluster pine ( $P$. pinaster Aiton) is one of the most iconic species of the western Mediterranean forest landscape. In Spain, it is the most widely distributed native pine ( $\sim 600,000$ ha of natural populations) and also the most widely used in reforestation. Maritime pine has been planted in temperate regions within and outside its natural range mainly because of its commercial importance and easy acclimation. In fact, outside its natural range, this species is considered one of the most relevant invasive plants in the world (Lowe et al., 2004). In the light of this, ecological information from natural populations of the species, in particular that related to seed dispersal and recruitment can be very useful for developing population dynamic and spread models (Rodríguez-García et al., 2010).

Success or failure of maritime pine regeneration is influenced by debris accumulation, and herbaceous and moss cover (Rodríguez-García et al., 2010). Nevertheless, water availability from precipitation is the most limiting factor for recruitment (Rodríguez-García et al., 2010, 2011; Ruano et al., 2009). Generally, post-harvest natural regeneration of this species is considered easy. However, nowadays, natural regeneration in large parts of $P$. pinaster distribution, such as on the dry (sandy) soils of the Spanish Northern Plateau, is not achieved satisfactorily, with several examples of poor regeneration (González-Alday et al., 2009; Serrada et al., 2008; Rodríguez-García et al., 2010). This limitation may compromise the sustainability of these stands, forcing alternatives such as seeding or planting (Gordo et al., 2012). Regeneration problems in dry sites will likely get worse by effect of global climate change, since seasonal droughts are expected to become longer and more intense. In these sites, an adequate amount of seed dispersed to suitable places results central to ensure natural regeneration.

The objectives of this study are (1) to describe seed dispersal patterns in Mediterranean maritime pine ( $P$. pinaster Aiton) from the Spanish Northern Plateau at different spatial and temporal scales, (2) to estimate its potential spread rates and (3) to analyse ecological implications of the described spread capability, in special those related to natural regeneration success and forest management. To achieve these objectives, we first developed a multiyear study of fecundity and seed dispersal in natural populations of this species using modelling techniques based on the spatial distribution of seeds (seed shadows) to simultaneously estimate fecundity and seed dispersal kernels. Second, we used the forest simulation model SORTIE-ND (Murphy, 2008) to assess $P$. pinaster spread rates under diverse cases of stand fertility, long-distance dispersal (LDD), and forest structure. Our study contributes to the understanding of the role of seed dispersal in the complex process of natural regeneration of $P$. pinaster in central Spain.

\section{Materials and methods}

\subsection{Study site and sampled stands}

The study was conducted in two natural $P$. pinaster stands (Coca, $41^{\circ} 16 \mathrm{~N}, 4^{\circ} 29 \mathrm{~W}$; and Cuéllar, $41^{\circ} 22 \mathrm{~N}, 4^{\circ} 29 \mathrm{~W}$ ) with a density ca. 110 trees/ha. Both are located in a flat sandy region in Mediterranean Central Spain (Fig. 1) and have trees $25-150$ years old. Management is based on natural regeneration following a shelterwood system adapted to resin production.

\subsection{Meteorological data}

Meteorological data for Cuéllar were extracted from daily measurements recorded in the Spanish forest damage monitoring

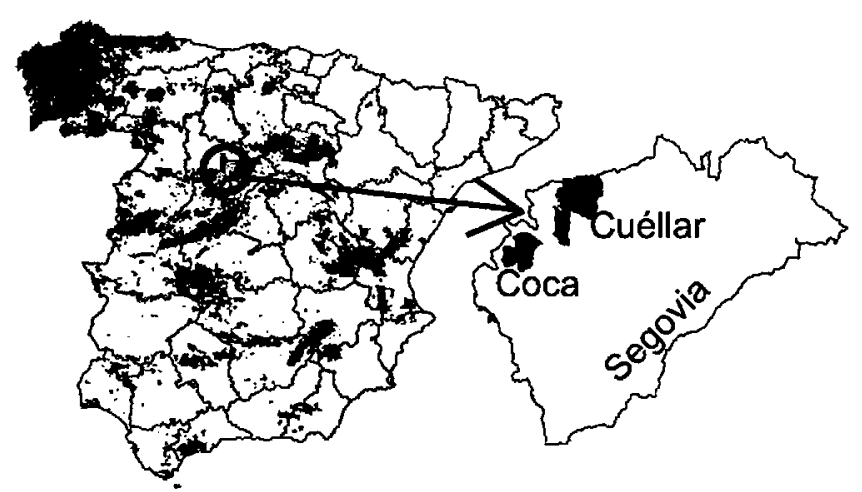

Fig. 1. Location map of experimental plots. The distribution range of Pinus pinaster (native and introduced) in Spain in also given (in grey on the map of Spain).

network (level II, 2004-2007) corresponding to this locality (Directorate for Nature Affairs and Forest Policy, www.marm.es). For Coca, rain data were taken from AEMET (Spanish National Meteorological Agency, http://www.aemet.es/). Specifically, we used the following variables: precipitation, maximum and mean temperature, and maximum and mean wind speed. Temperature and wind data for 2007 were not available for Coca.

\subsection{Experimental design and measurements}

Seed dispersal was studied in Coca during the years 2000, 2006 and 2007 (CO00, Co06 and Co07, respectively) and in Cuéllar from 2004 to 2007 (Cu04, Cu05, Cu06 and Cu07). In the year 2000, we placed 28 square $\left(1 \times 1 \mathrm{~m}^{2}\right)$ traps in a $30 \mathrm{~m}$ radius plot in Coca. As numbers of collected seeds were low that year, in 2006 and 2007 seed deposition was measured by placing 45 traps of bigger size $\left(1.5 \times 1.5 \mathrm{~m}^{2}\right)$, which were situated in a $75 \mathrm{~m}$ radius plot. Traps in Coca were visited weekly from May to October, covering the main seed dispersal period, and all seeds were collected and counted. In Cuéllar, we placed 90 square $\left(1 \times 1 \mathrm{~m}^{2}\right)$ traps across an area of 11.4 ha. Seeds were collected in Cuéllar every 15 days from January 2004 to December 2007.

In both stands, polar coordinates of all trees and traps were taken, and age, total height and diameter (at $1.30 \mathrm{~m}$ ) were measured. To get an estimate of the relative contribution of each tree to the seed crop, cones on all trees were counted in Coca $(n=362)$ in the springs of 2000 (Miguel-Pérez et al., 2002), 2006 and 2007, and on a large tree sample in Cuéllar $(n=212)$ in the spring of 2004. In CoOO and Cu04 only the cones in half of the crown were counted, using a conversion coefficient to estimate the cones on the whole crown (Miguel-Pérez et al., 2002). All traps were protected from seed predators with a net of $1 \mathrm{~cm}^{2}$ mesh.

\subsection{Seed dispersal kernels}

In absence of molecular marker data, modelling techniques (conventionally named 'inverse modelling', IM) were used to adjust dispersal kernels. We built a classical seed dispersal model by assuming all trees dispersed their seeds according to a probability density function for the random dispersal distance $r$. Three dispersal kernels with two unknown parameters (namely the scale parameter $u$ and the shape parameter $p$ ) were examined and compared. (1) The exponential kernel that was developed by Ribbens et al. (1994) and later modified by Clark et al. (1998), whose equation we use here:

$f(r)=\frac{p}{2 \pi u^{2} \Gamma(2 / p)} \exp \left[-\left(\frac{r}{u}\right)^{p}\right]$,

(2) the lognormal kernel (Greene and Johnson, 1989): 
Table 1

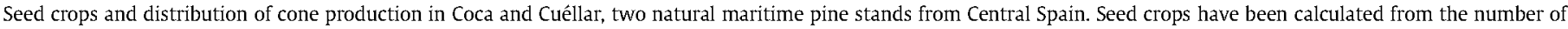
cones.

\begin{tabular}{|c|c|c|c|c|c|c|c|c|}
\hline \multirow[t]{2}{*}{ Population } & \multirow[t]{2}{*}{ Year } & \multirow{2}{*}{$\begin{array}{l}\text { Seed crop (seed/ } \\
\left.m^{2}\right)\end{array}$} & \multirow{2}{*}{$\begin{array}{l}\text { Average number of cones per } \\
\text { tree }\end{array}$} & \multirow{2}{*}{$\begin{array}{l}\text { Maximum number of cones } \\
\text { per tree }\end{array}$} & \multicolumn{4}{|c|}{ Distribution of cone production (\% of trees) } \\
\hline & & & & & $\begin{array}{l}\text { Non } \\
\text { reproductive }\end{array}$ & $\begin{array}{l}1-9 \\
\text { cones }\end{array}$ & $\begin{array}{l}10-40 \\
\text { cones }\end{array}$ & $\begin{array}{l}\text { More than } 40 \\
\text { cones }\end{array}$ \\
\hline Coca & 2000 & 15.9 & $17.84 \pm 15.32$ & 86 & 6.1 & 22.8 & 62.1 & 9.0 \\
\hline Cuéllar & 2004 & 12.3 & $14.71 \pm 14.56$ & na & 5.2 & 41.8 & 46.1 & 6.9 \\
\hline Coca & 2006 & 5.2 & $5.87 \pm 7.15$ & 68 & 25.7 & 51.4 & 22.5 & 0.3 \\
\hline Coca & 2007 & 3.8 & $4.30 \pm 5.11$ & 33 & 26.6 & 61.8 & 11.6 & 0.0 \\
\hline
\end{tabular}

$f(r)=\frac{1}{(2 \pi)^{3 / 2} p r^{2}} \exp \left[-\frac{(\ln r-u)^{2}}{2 p^{2}}\right]$

and (3) the '2Dt' function, developed by Clark et al. (1999). The 2Dt is a Gaussian kernel where the shape parameter is allowed to vary over distance $r$ :

$f(r)=\frac{p}{\pi u\left(1+\frac{r^{2}}{u}\right)^{p+1}}$,

where $r$ denotes the distance a seed travels. In IM techniques, tree fecundity is usually estimated using linear models with basal area, although there are other options. In some cases, ecologists prefer to conduct direct cone counts on the tree crown (Sagnard et al., 2007) or use models to independently estimate seed production (Calama et al., 2008 for $P$. pinea). When reproductive success is weakly or moderately related to tree size, Nanos et al. (2010) suggest using the unrestricted fecundity (UF) model, which allows fecundities to vary freely from one tree to another and even to be null. In this study, we tested two approaches to estimate tree fecundity: the linear models with basal area and the direct cone counts. Despite the latter being suggested to produce more stable estimations (Manso et al., 2012), the basal area model was eventually chosen, as convergence could not be obtained in Coca using direct counts.

Parameter estimation was based on maximum likelihood assuming that the expected number of seeds arriving in a seed trap is Poisson-distributed and by approximating the likelihood numerically. Negative binomial distribution was also used, but the fits were statistically superior and ecologically more meaningful when the Poisson distribution was chosen instead.

The best-fitting dispersal kernels were chosen based on the negative log-likelihood score (NLL) and the correlation coefficient between the number of observed seed counts in the seed traps and the number predicted by the model. In total, we fitted seven dispersal kernels, one for each dispersal season studied in each site (i.e. four in Cuéllar and three in Coca). For Cuéllar, we were also able to compute intra-season seed dispersal kernels, considering maximum periods of seed dispersal within each year (more than 100 seeds trapped between two consecutive inventories). Parameter estimates and dispersal distances calculated from intra-season seed dispersal kernels were subsequently correlated with dispersal-season climatic variation, such as accumulated daily rainfall and peak wind between field inventories.

\subsection{SORTIE model simulations}

We simulated different scenarios to analyse the influence of mating system and dispersal parameters on $P$. pinaster natural regeneration dynamics using SORTIE-ND v.6.09, which is an individual tree, spatially-explicit mixed-species forest model that makes predictions at the tree and stand levels (Coates et al., 2003; Pacala et al., 1993; Pedersen, 2007). The model works by creating individual virtual trees which are subjected to biological processes called 'behaviours', such as growth, recruitment, mortality, light or substrate. We focused on the 'recruitment' behaviour, which predicts the density of seedlings produced by a tree as a function of the size of the tree and the distance from the tree (the 'seedling shadow'). The 'disperse' behaviour was based on the location and size of parent trees, and on lognormal dispersal kernels to determine the number and placement of seeds. The kernel fitted for $\mathrm{CuO} 4$ was considered the most representative of the two P. pinaster stands studied (see Section 4.2) and was used in all models. The 'establishment' behaviour was used to control the losses occurred between dispersal and effective recruitment (0.001 in González-Martínez et al., 2006) and the 'mortality' behaviour (senescence) to model death of adult trees. The remainder parameters in the model were considered to be similar to other pines.

A basic (control) simulation was carried out and subsequent simulations were performed changing initial parameters such as density ( 100 and 300 trees/ha), initial population size ( 2 and 5 ha stands) and fertility (double or half the observed levels in the experimental sites). In another set of simulations we included 10 , 20 or 50 random LDD events. These LDD events were placed in the simulations stochastically using random Poisson distributions to determine the number of dispersal events that may occur at 100,500 or $1000 \mathrm{~m}$ away from seed sources. This amount of LDD can be considered moderate $(\sim 1$ to 5 every $7 \times 104$ dispersal events; see Nathan et al., 2008; Kremer et al., 2012, and references therein). Five replicated simulations of 500 years were run for each parameter combination.

\section{Results}

\subsection{Fertility estimates based on observed cone production}

In Coca, cone production was variable across years (Table 1 ). Counts of non-reproductive individuals were lower in $2000(6.1 \%$ of trees) than in $2006(25.7 \%)$ or 2007 (26.6\%). For those trees producing cones, 2000 was also more productive $(71 \%$ of trees with more than 10 cones), with Co07's crop being the less abundant of all (no tree above forty cones and the majority below ten; Table 1). Since the mean number of seeds per cone was $\sim 94.7$ (SD: 11.6 , $n=11$ ) and the estimated percentage of empty seeds in this population is $\sim 16.4 \%$ (Miguel-Pérez et al., 2002), the mean overall seed production in Coca ranged from 15.6 seeds $/ \mathrm{m}^{2}$ in 2000 to 3.8 seeds $/ \mathrm{m}^{2}$ in 2007.

In Cuêllar, the estimated seed production in 2004 (Cu04) was similar to the one in 2000 in Coca ( $\mathrm{COON})$ and much higher than those observed in $\mathrm{COO} 6$ and $\mathrm{CO07}$. These among-site differences in female fertility were also reflected in fertility estimates from best fitting dispersal kernels, which showed seed crops 3-4 times bigger in Cuéllar than in Coca (see Table 4). However, substantial differences between fertility estimations via basal area and those obtained by direct counts were found in some cases, with modelling producing fertility estimates for Cu04 over twofold those in $\mathrm{COOO}$ and more similar fertility estimates across Coca crops.

Remarkably, we found a highly skewed distribution of female reproductive effort, as estimated by cone counts. Only a few mother trees were responsible for most cones produced in the stand. We estimated that half the crop was produced in Coca by 
Table 2

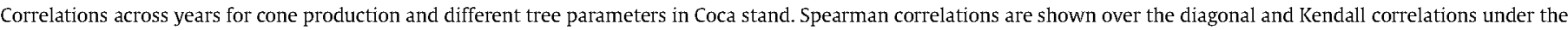
diagonal; DBH: diameter at $1.30 \mathrm{~m}$; HT: total height; $\mathrm{AG}$ : annual growth.

\begin{tabular}{|c|c|c|c|c|c|c|c|}
\hline & \multicolumn{3}{|c|}{ Cone production } & \multicolumn{4}{|c|}{ Tree features } \\
\hline & 2000 & 2006 & 2007 & DBH & Age & HT & $A G$ \\
\hline \multicolumn{8}{|c|}{ Cone production } \\
\hline 2000 & & $0.350^{* * *}$ & $0.409^{* * * *}$ & $0.159^{* *}$ & $-0.129^{* *}$ & $-0.119^{* *}$ & $0.144^{* * *}$ \\
\hline 2006 & $0.256^{* * *}$ & & $0.549^{* * * *}$ & $0.041^{\mathrm{ns}}$ & $-0.047^{\mathrm{ns}}$ & $-0.146^{* * *}$ & $0.240^{* * * *}$ \\
\hline 2007 & $0.307^{* * k+}$ & $0.423^{* * *}$ & & $0.110^{* * *}$ & $0.002^{\text {ns }}$ & $0.047^{\mathrm{ns}}$ & $0.166^{* *}$ \\
\hline \multicolumn{8}{|c|}{ Tree features } \\
\hline $\mathrm{DBH}$ & $0.110^{* * * *}$ & $0.029^{\mathrm{ns}}$ & $0.077^{* *}$ & & & & \\
\hline Age & $-0.085^{* *}$ & $-0.033^{\mathrm{ns}}$ & $0.001^{\mathrm{ns}}$ & & & & \\
\hline HT & $-0.082^{* *}$ & $-0.102^{* * *}$ & $0.032^{\mathrm{ns}}$ & & & & \\
\hline$A G$ & $0.099^{* * *}$ & $0.170^{* * *}$ & $0.119^{* * *}$ & & & & \\
\hline
\end{tabular}

ns: Non-significant.

${ }^{*} 0.05<p<0.10$.

** $0.01<p<0.05$

${ }^{* * *} p<0.01$

Table 3

Collected seeds in Coca and Cuêllar study sites from 2000 to 2007.

\begin{tabular}{|c|c|c|c|c|c|c|c|c|}
\hline \multirow[t]{2}{*}{ Site } & \multirow[t]{2}{*}{ Year } & \multirow[t]{2}{*}{ Code } & \multicolumn{4}{|l|}{ Collected seeds } & \multirow[t]{2}{*}{ Seeds/trap } & \multirow[t]{2}{*}{ Seeds $/ \mathrm{m}^{2}$} \\
\hline & & & Area sampled $\left(\mathrm{m}^{2}\right)$ & $\mathrm{N}$ & Largest dispersal period (\%) & Second largest dispersal period (\%) & & \\
\hline \multirow[t]{3}{*}{ Coca } & 2000 & $\mathrm{CoOO}$ & 28.00 & 231 & $53(22.9)$ & $48(22.8)$ & $7.22 \pm 4.09$ & $7.22 \pm 4.09$ \\
\hline & 2006 & Co06 & 101.25 & 946 & $295(31.2)$ & na & $21.31 \pm 16.70$ & $9.47 \pm 7.43$ \\
\hline & 2007 & $\mathrm{CoO} 7$ & 101.25 & 500 & $162(32.4)$ & na & $11.11 \pm 7.14$ & $4.94 \pm 3.17$ \\
\hline \multirow[t]{4}{*}{ Cuêllar } & 2004 & Cu04 & 90.00 & 1148 & $352(33.5)$ & $187(17.8)$ & $12.76 \pm 8.87$ & $12.76 \pm 8.87$ \\
\hline & 2005 & Cu05 & 90.00 & 1598 & $616(38.5)$ & $168(10.5)$ & $17.76 \pm 10.26$ & $17.76 \pm 10.26$ \\
\hline & 2006 & Cu06 & 90.00 & 1307 & $409(31.3)$ & $240(18.4)$ & $14.52 \pm 10.79$ & $14.52 \pm 10.79$ \\
\hline & 2007 & Cu06 & 90.00 & 1228 & $420(34.2)$ & $238(19.4)$ & $13.64 \pm 9.06$ & $13.64 \pm 9.06$ \\
\hline
\end{tabular}

na: Not possible to estimate.

the $22.8 \%, 15.6 \%$ and $18.5 \%$ most productive trees in 2000,2006 and 2007, respectively, and by $19 \%$ of the trees in Cu04. In Coca, individual cone production was correlated across years, with high fertility trees remaining the same, in particular in years 2006 and 2007 (Table 2). In addition, we found significant correlations between the number of cones per tree and tree attributes, such as diameter and annual growth.

\subsection{Seed shadows and phenology of dispersal}

In total, we collected 6958 seeds (1677 in Coca and 5281 in Cuéllar), which sum up to annual averages of 14.67 seeds $/ \mathrm{m}^{2}$ in Cuéllar (four year average) and about half that amount (7.21 seeds $/ \mathrm{m}^{2}$ ) in Coca (three year average). There were also notable differences across years within sites (Table 3 ). Overall, maximum differences found between two seed crops were 3.6-fold, from 4.94 seeds $/ \mathrm{m}^{2}$ in $\mathrm{Co} 07$ to 17.76 seeds $/ \mathrm{m}^{2}$ in Cu05. Fertility estimates based on seed traps were relatively similar to those based on direct cone counts, except for CoOD.

In a 'regular' year, most dispersal events were concentrated on the months of June, July and August (Fig. 2). However, variability across seasons was high. For example, in 2007 there was practically no seed rain until July and the maximum dispersal happened a month later than the other years, and in 2005 the dispersal season finished around the middle of August, one month before than expected. In Cuéllar, there were always two seed rain peaks, the first one being more pronounced than the second. In Coca, in contrast, seed dispersal distributions were more irregular.

\subsection{Seed dispersal kernels}

Dispersal kernel fits were always better for Cuéllar than for Coca (Table 4 and Fig. 3). The lognormal model was always the best-fitting one in Cuéllar, having the lowest NLL and the highest correlation values. Although we selected the best model each year, scale and shape parameters were relatively constant for all years in this site. Distributions of 2Dt type, however, gave the best fit for seed dispersal kernels in Coca and kernels using this model were the only ones biologically meaningful in two (Co06 and Co07) out of the tree years fitted for this site.

The best-fitting seed dispersal kernels can be classified in three groups according to kernel shape (Fig. 3), with models built for Cu04, Cu05 and CoO0 showing intermediate seed dispersal probability functions (Table 4). Log-normal kernels for Cu06 and Cu07 have slightly higher shape parameters, which thickens the far tail while pushing the modal density backwards towards the mother tree. In contrast, 2Dt kernels for Coca in the same years (Co06 and Co07) have large scale parameters and extended far tails (Table 4). Median dispersal distances varied from $14.10 \mathrm{~m}$ in CoO0 to a maximum of $24.53 \mathrm{~m}$ in $\mathrm{Cu} 05$, with an average across years and sites of $20.29 \pm 3.97 \mathrm{~m}$.

Median dispersal distances varied notably among dates within dispersal seasons, for example from 9.96 to $32.37 \mathrm{~m}$ in $\mathrm{CuO} 4$ and from 12.24 to $54.91 \mathrm{~m}$ in Cu05 (Fig. 4). Among the fitted intraseasonal kernels in Cuéllar, the one corresponding to 18th June 2005 stands out because of its largest fecundity (i.e. seeds available for dispersal) and median dispersal distances, 6574 and $54.91 \mathrm{~m}$, respectively.

\subsection{Correlations with climatic events}

Meteorological data was used to correlate seed dispersal parameters with climatic events. A significant non-parametric Spearman correlation of $0.39(n=49, p$-value $=0.008)$ was found between dispersed seeds (i.e. collected in seed traps) and precipitation (daily rainfall sums). Moreover, intra-seasonal median 
Table 4

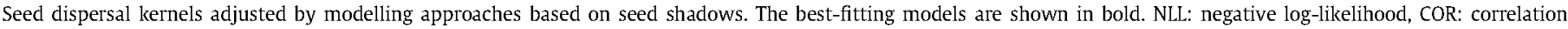
coefficient between the number of seeds observed and predicted by the model.

\begin{tabular}{|c|c|c|c|c|c|c|c|c|c|c|c|}
\hline \multirow[t]{2}{*}{ Site } & \multirow[t]{2}{*}{ Year } & \multirow[t]{2}{*}{ Code } & \multirow[t]{2}{*}{ Model } & \multirow[t]{2}{*}{ Fecundity (fitted) } & \multicolumn{2}{|c|}{ Kernel parameters } & \multicolumn{3}{|c|}{ Dispersal distance (m) } & \multirow[t]{2}{*}{ NLL } & \multirow[t]{2}{*}{ COR } \\
\hline & & & & & Scale & Shape & Mode & Median & Average & & \\
\hline \multirow[t]{9}{*}{ Coca } & \multirow[t]{3}{*}{2000} & \multirow[t]{3}{*}{$\mathrm{CoOO}$} & Ribbens & 5028.00 & 5.26 & 0.87 & na & na & na & -203.18 & 0.46 \\
\hline & & & log-norm & 5213.97 & 2.63 & 1.13 & 3.86 & 13.87 & 26.27 & -203.35 & 0.45 \\
\hline & & & $2 \mathrm{Dt}$ & 5558.69 & 47.24 & 0.42 & na & 14.10 & na & -203.61 & 0.47 \\
\hline & \multirow[t]{3}{*}{2006} & \multirow[t]{3}{*}{ Co06 } & Ribbens & 6474.61 & 31.40 & 34.87 & na & na & na & -1984.51 & 0.46 \\
\hline & & & log-norm & 6530.32 & 3.07 & 0.49 & 16.94 & 21.54 & 24.28 & -1971.65 & 0.40 \\
\hline & & & $2 \mathrm{Dt}$ & 6523.88 & 3651.70 & 5.58 & na & 21.98 & na & -1969.37 & 0.39 \\
\hline & \multirow[t]{3}{*}{2007} & \multirow[t]{3}{*}{$\mathrm{CoO} 7$} & Ribbens & 3443.84 & 32.41 & 28.30 & na & na & na & -730.96 & 0.47 \\
\hline & & & $\log$-norm & 3395.24 & 3.29 & 0.14 & na & na & na & -731.60 & 0.46 \\
\hline & & & 2Dt & 3477.40 & 3214.53 & 4.37 & na & 23.51 & na & -727.90 & 0.46 \\
\hline \multirow[t]{12}{*}{ Cuêllar } & \multirow[t]{3}{*}{2004} & \multirow[t]{3}{*}{ Cu04 } & Ribbens & 13204.70 & 1.03 & 0.49 & na & na & na & -1954.11 & 0.55 \\
\hline & & & log-norm & 13402.68 & 2.75 & 1.13 & 4.36 & 15.64 & 29.62 & -1955.38 & 0.56 \\
\hline & & & $2 \mathrm{Dt}$ & 12385.06 & 5180.10 & 10.05 & na & na & na & -1937.55 & 0.48 \\
\hline & \multirow[t]{3}{*}{2005} & \multirow[t]{3}{*}{ Cu05 } & Ribbens & 18507.28 & 0.43 & 0.40 & na & na & na & -3238.63 & 0.59 \\
\hline & & & log-norm & 19540.71 & 3.20 & 1.34 & 4.07 & 24.53 & 60.21 & -3239.08 & 0.59 \\
\hline & & & $2 \mathrm{Dt}$ & 16924.20 & 5621.05 & 7.51 & na & na & na & -3228.41 & 0.54 \\
\hline & \multirow[t]{3}{*}{2006} & \multirow[t]{3}{*}{ Cu06 } & Ribbens & 17543.24 & 0.00 & 0.21 & na & na & na & -2567.24 & 0.46 \\
\hline & & & log-norm & 17792.39 & $\mathbf{3 . 1 0}$ & 1.59 & 1.77 & 22.20 & 78.57 & -2568.75 & 0.47 \\
\hline & & & $2 \mathrm{Dt}$ & 14567.58 & 4925.81 & 6.76 & na & na & na & -2535.13 & 0.38 \\
\hline & \multirow[t]{3}{*}{2007} & \multirow[t]{3}{*}{ Cu07 } & Ribbens & 16130.64 & 0.00 & 0.19 & na & na & na & -2242.41 & 0.65 \\
\hline & & & log-norm & 16214.09 & 3.00 & 1.64 & 1.36 & 20.09 & 77.08 & -2243.37 & 0.66 \\
\hline & & & $2 \mathrm{Dt}$ & 13180.65 & 4773.40 & 6.99 & na & na & na & -2194.95 & 0.47 \\
\hline
\end{tabular}

na: Not possible to estimate or without biological meaning.

dispersal distances (estimated only in Cuéllar) were correlated with maximum wind speed of the period considered (Spearman correlation of $0.58 ; n=17 ; p$-value $=0.019$ ).

\subsection{Dispersal models and spread rates}

Basic (control) simulation models showed that, given the dispersal parameters obtained experimentally in our study, and under the theoretical conditions represented by the current parameterization of SORTIE-ND, maritime pine is capable of occupying an area of $\sim 30$ ha along 500 years, with a rate of spread slightly higher than $1.1 \mathrm{~m} /$ year (Table 5). Starting tree density did not affect spread rates while increased fertility led to 2.5 -fold occupied area. Other factors, such as percentage of trees located outside the initial stand or maximum establishment distance, also displayed higher values with increased fertility.

Long-distance dispersal (LDD) played a key role in natural regeneration, as expected. Simulations considering LDD resulted in occupied areas as large as $\sim 290$ ha in the 50 simulated LDD-events case (Table 5 ). The maximum distance reached by a single tree in this set of simulations was of $\sim 2 \mathrm{~km}$, with about fourfold spread rates ( $3.8 \mathrm{~m} /$ year) compared to simulations that did not consider LDD.

\section{Discussion}

\subsection{Female fertility and seed dispersal across years and sites}

Cone production was scarce in the Coca and Cuéllar stands, especially in 2006 and 2007 . Higher cone production has been reported for other pine species (e.g. 27.7 cones per tree for P. palustris; Grace et al., 2004 and 242.3 cones per tree for Pinus halepensis; Nathan et al., 1999) and for maritime pine seed orchards in northern Spain (average of 40 cones per tree; Merlo and Fernández-López, 2004). In the later study, an exceptional crop with 65 cones per tree was also observed, probably due to climatic factors, masting or as a response to an intensive harvesting carried out two years before (Merlo and Fernández-López, 2004). In $P$. halepensis, also a Mediterranean pine, local tree density is inversely correlated with seed production (Schurr et al., 2008).
With regards to $P$. pinaster, natural regeneration is considered successful when the final density of seedlings from 8 to 10 years old is over 2000 trees/ha (Gordo et al., 2012). According to the cone production data obtained by our study and taking into account a typical regeneration period of 20 years, we can conclude that the amount of dispersed seed is not a limiting factor for the natural regeneration process in the Spanish Northern Plateau.

Interannual variation in cone production was remarkable. In Co00, cone production was more than three times that of Co06 and $\mathrm{Co} 07$. High inter-annual variability in cone production has also been reported in other Mediterranean pines. For example, 50 -fold differences in cone crop along a period of 6 years have been reported for Pinus pinea, mainly as a direct response to climatic factors during cone development (e.g. winter rainfall; Calama et al., 2011) and resources depletion (Mutke et al., 2005). In Pinus nigra, Tiscar Oliver (2007) found 877 seeds $/ \mathrm{m}^{2}$ one year but no seed production the next two years.

The beginning and end of the dispersal season, as well as its length, varied also across years and stands in our study, with differences in maximum dispersal of over 30 days depending on the season/stand. These differences were probably caused by climate, as suggested previously (Manso et al., 2012); in particular, we found a correlation between precipitation and seed rain in $P$. pinaster, similarly to the patterns found by Manso et al. (2012) in $P$. pinea. These findings suggest a synchronic pattern of seed rain with precipitation in Mediterranean pines. Moreover, in P. pinaster, the effect of precipitation together with the significant correlation between intra-seasonal median dispersal distances and maximum wind speed point to violent summer storms as the main driver of $P$. pinaster seed dispersal in the study region.

Dispersal events in $P$. pinaster were concentrated in only one period, from June to August; a similar pattern was found in P. nigra, in which seed release occurs from January to April, with $3 / 4$ of the total number of seeds dispersed from the beginning of February to the end of March (Tiscar Oliver, 2007). However, seed release in other Mediterranean pines can occur twice a year, e.g. in association with seasonal Sharav events in spring and autumn in P. halepensis (Nathan et al., 1999).

Seed dispersal kernels estimated median dispersal distances in $P$. pinaster from 14.1 to $24.5 \mathrm{~m}$, with an intraseasonal maximum of 


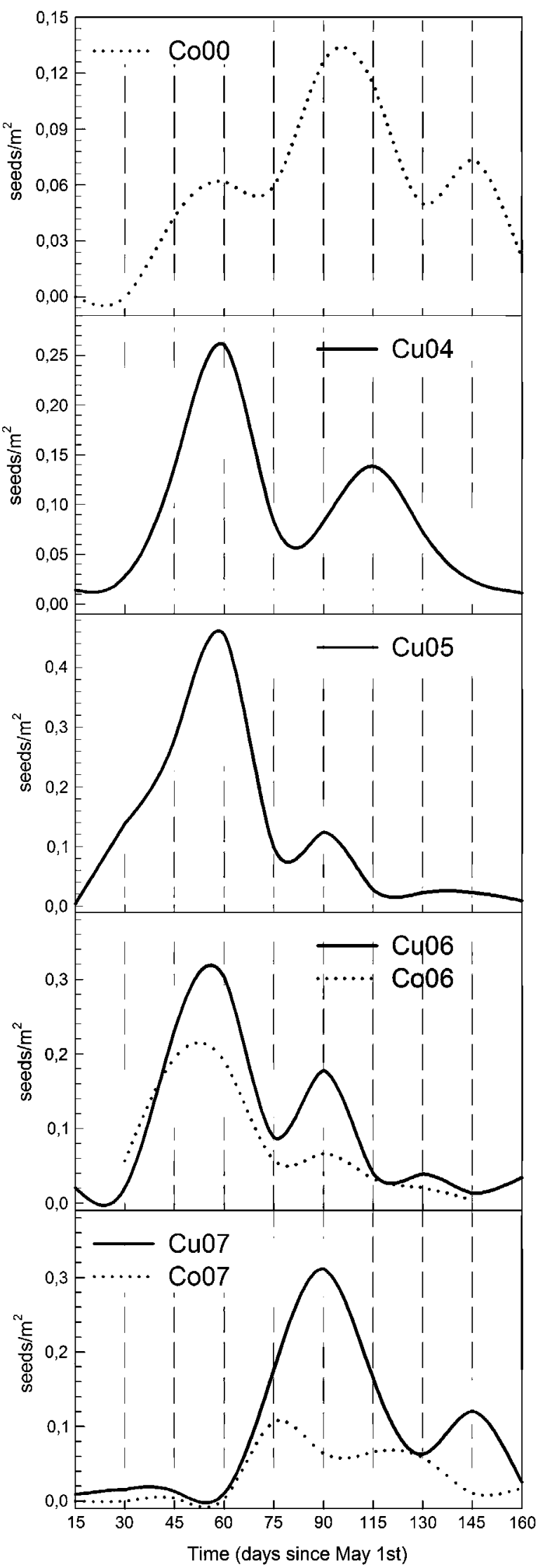

Fig. 2. Seed rain intraseasonal variation by site and year. Continuous lines are used for Cuéllar and dotted lines for Coca. Note the different scale.
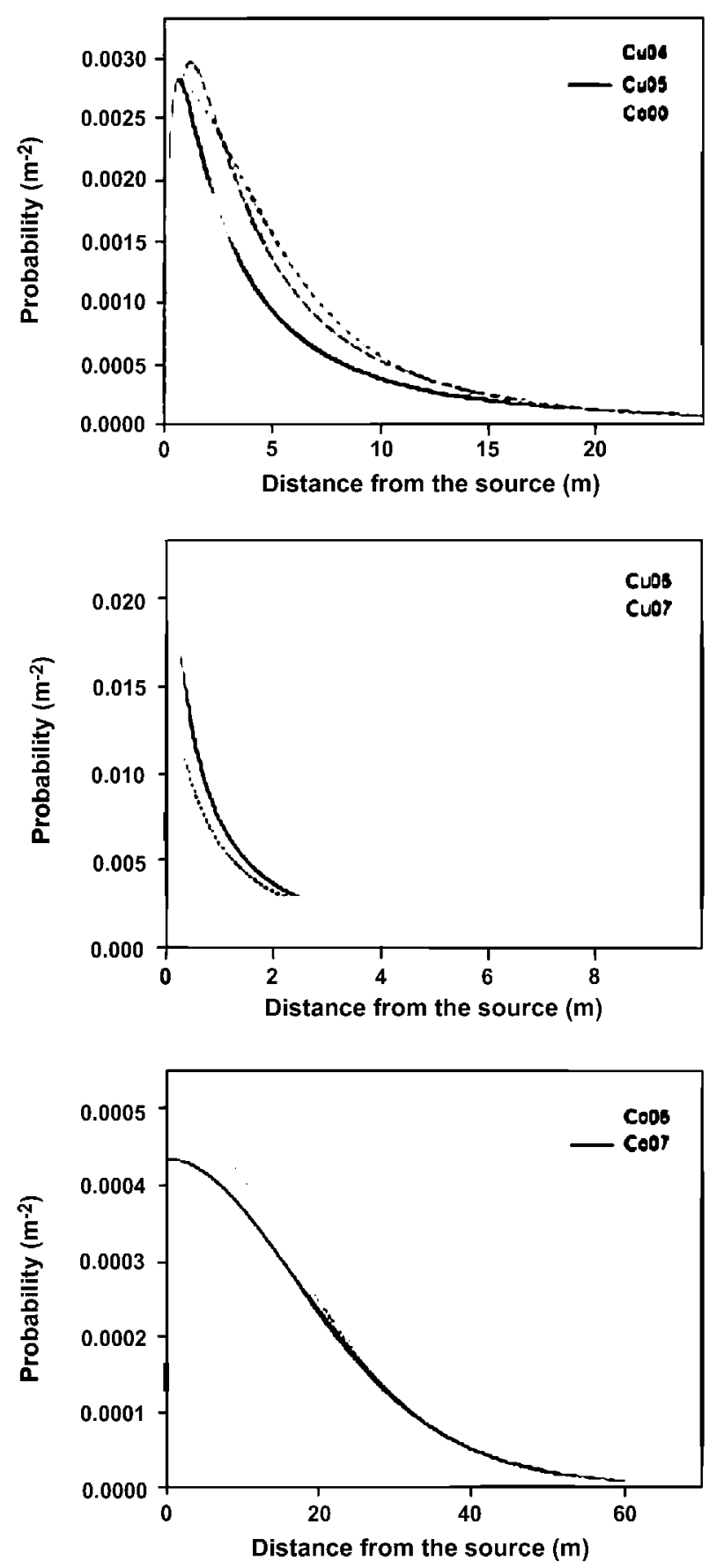

Fig. 3. Seed dispersal kernels grouped according to its functional shape.

$54.9 \mathrm{~m}$. Similar dispersal distances have been reported for other wind-dispersed conifers, for example 4.3-17.4 $\mathrm{m}$ for Picea abies (Dovčiak et al., 2008), $16 \mathrm{~m}$ for Pinus strobus (Ribbens et al., 1994) or $42 \mathrm{~m}$ for Pinus palustris (Grace et al., 2004). In P. halepensis, only $2.7 \%$ of the seeds travelled more than $20 \mathrm{~m}$ (Nathan et al., 2000). Reported dispersal distances are often much larger for animal-dispersed trees. For example, García et al. (2007) found median seed dispersal distances of $145.2 \mathrm{~m}$ in Prunus mahaleb, a Mediterranean wild cherry tree. Inter-annual differences in dispersal distance were noticeable (from $14.1 \mathrm{~m}$ in Co00 to $23.5 \mathrm{~m}$ in $\mathrm{Co} 07$ or from $15.6 \mathrm{~m}$ in $\mathrm{Cu04}$ to $24.5 \mathrm{~m}$ in $\mathrm{Cu} 05$ ) and were also found among dates within a single dispersal season (see Fig. 4). 


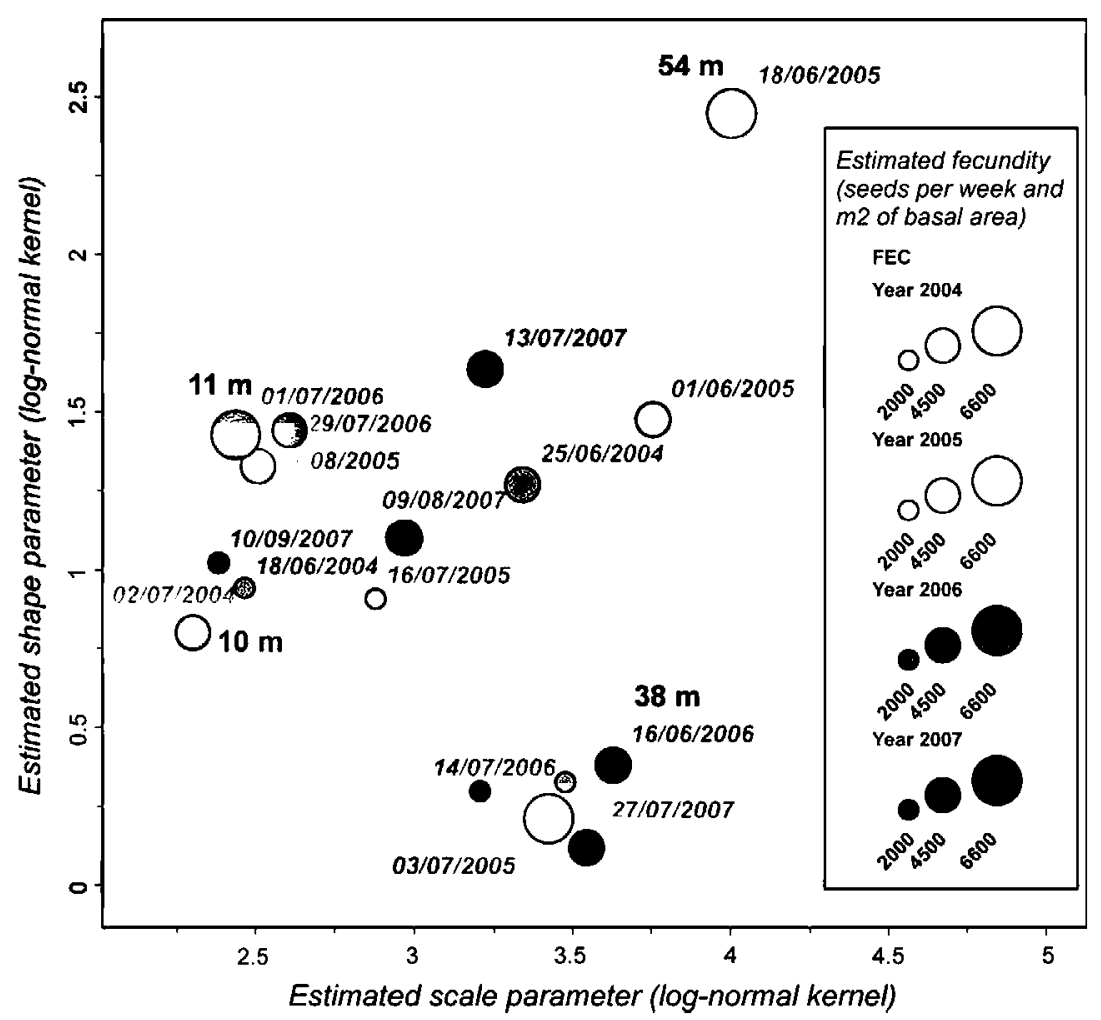

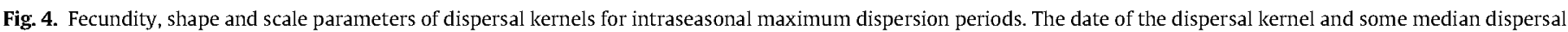
distances are marked. Median dispersal distance increases with higher values of scale and shape parameter.

Table 5

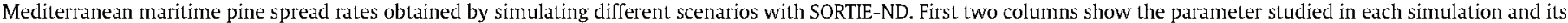
value.

\begin{tabular}{|c|c|c|c|c|}
\hline Simulation set & Parameter value & Area invaded (ha) & $\%$ Trees out of initial stand & Maximum distance to source (m) \\
\hline Basic & 200 trees/ha ( 1 ha) & $30.87 \pm 7.96$ & 52.1 & 555.5 \\
\hline \multirow{2}{*}{ Density } & 100 trees/ha ( 1 ha) & $18.04 \pm 3.72$ & 51.5 & 422.4 \\
\hline & 300 trees/ha ( 1 ha) & $46.82 \pm 21.52$ & 52.0 & 520.5 \\
\hline \multirow[t]{2}{*}{ Area } & 200 trees/ha (2 ha) & $34.56 \pm 4.18$ & 35.4 & 456.1 \\
\hline & 200 trees/ha (5 ha) & $56.72 \pm 7.60$ & 21.9 & 526.2 \\
\hline \multirow[t]{2}{*}{ Fertility } & Double the basic simulation & $76.35 \pm 8.04$ & 55.7 & 594.9 \\
\hline & Half the basic simulation & $8.31 \pm 1.89$ & 46.8 & 278.9 \\
\hline \multirow[t]{3}{*}{ LDD } & 10 LDD events & $93.49 \pm 23.87$ & 51.5 & 1157.6 \\
\hline & 20 LDD events & $141.14 \pm 40.75$ & 53.1 & 1175.1 \\
\hline & 50 LDD events & $292.27 \pm 30.41$ & 52.3 & 1918.9 \\
\hline
\end{tabular}

In our study, intraseasonal differences in dispersal distances can be explained, at least partially, by maximum wind speed during dispersal, a pattern that has also been reported by other authors (Higgins et al., 2003; Nathan et al., 1999, 2000).

\subsection{Choice of seed dispersal kernels in Coca and Cuéllar}

Lognormal seed dispersal kernels were chosen for Cuéllar because of slightly lower NLLs and, mainly, a better correlation between the number of seeds observed and predicted by the model, while we chose the 2Dt model for Coca because it was the only one with biological meaning (others produced unrealistic kernels with high probability of dispersing all seeds to similar distances from the mother tree). The lognormal model has been commonly used to describe dispersal functions, in particular for tree species. For example, Greene et al. (2004) pointed that the lognormal is preferred to other two-parameter functions (Weibull and 2Dt) for wind-dispersed species because, apart from providing a framework for mechanistic interpretation, it tends to provide a closer approximation to observed dispersal curves.

The 2Dt dispersal kernel predicts convexity at the source and a fat tail (Clark et al., 1999). This type of function has been used in several other studies of seed dispersal too (Greene et al., 2004; Jones et al., 2005; Schurr et al., 2008). As the 2Dt model can simultaneously capture the shape of the curve both 'near and far' (Clark et al., 1999), we speculate that the 2Dt model fits better in Coca because, in this site, sampling was based on a lower number of traps, which may have resulted in a reduced collection of seeds that travelled intermediate distances.

One possible cause of differences in the shape of best-fitting seed dispersal kernels across sites and years could be related to sampling design. Indeed, $\mathrm{C} 006$ and $\mathrm{C} 007$ had the same design and kitted similar curves whereas Co00, based on a sampling design with less sampling effort, yield greater differences in terms of estimated curve parameters. In the case of Cuéllar, the sampling design was always the same, which apparently resulted in fairly 


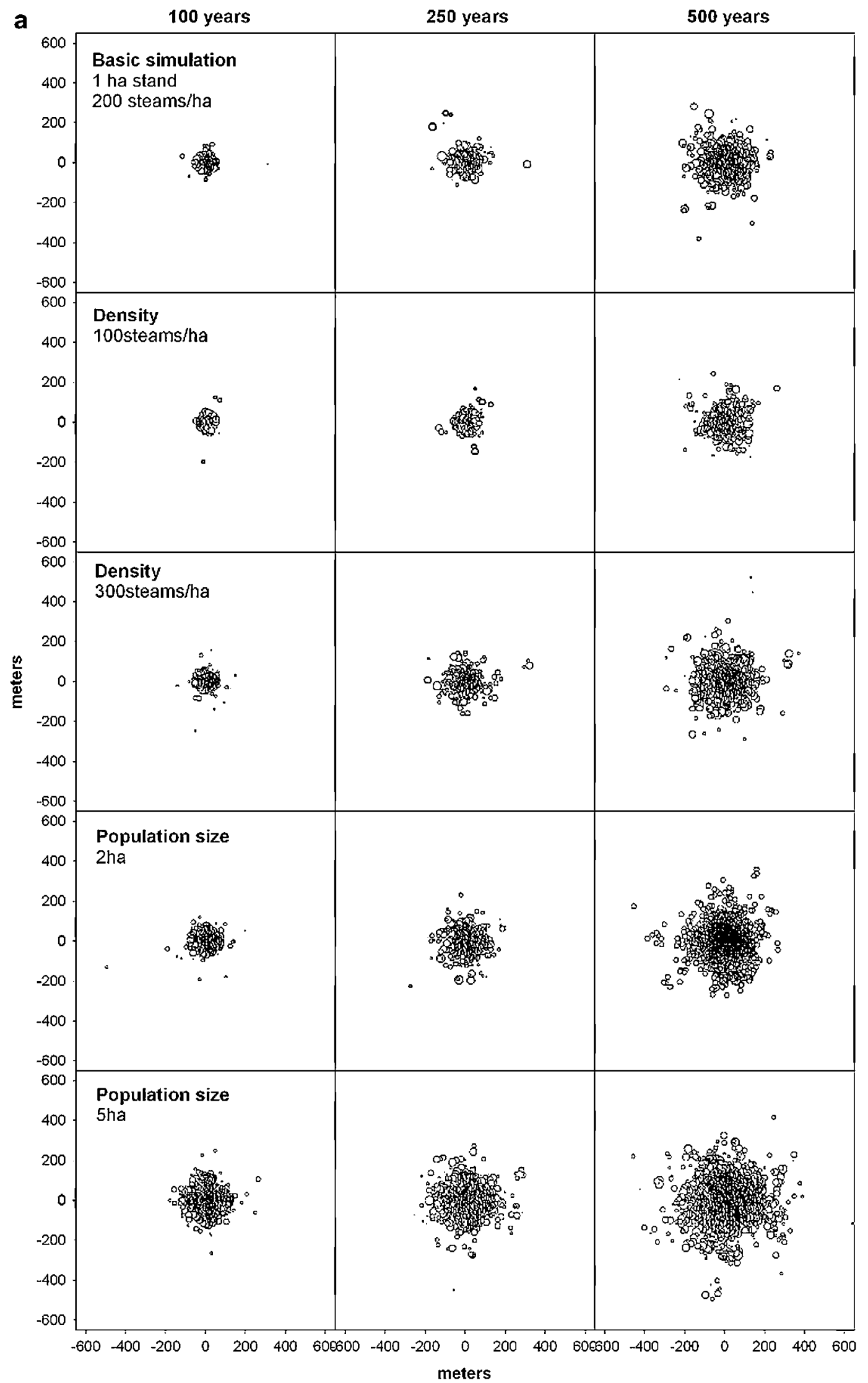

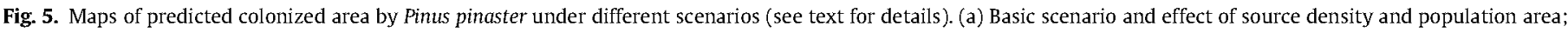
(b) Fecundity effects; (c) Basic model including some moderate (in terms of number and distance reached) LDD events. 


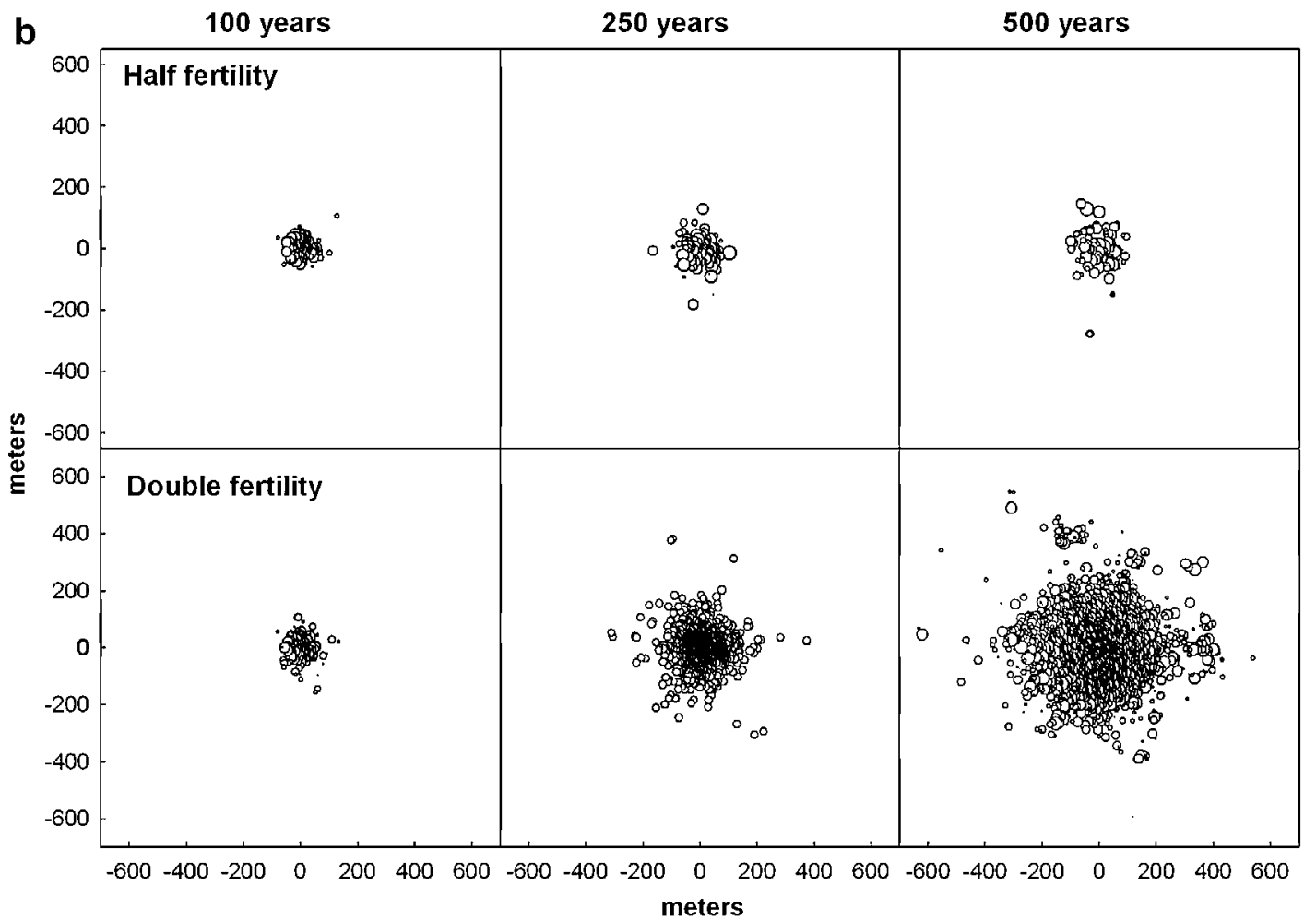

Fig. 5 (contimued)

stable shape and scale parameter estimation across years and among seasons within years. This fact agrees with RobledoArnuncio and Garcia (2007) findings suggesting that dispersal curve fitting can be biased by the sampling method. Bias and inaccuracy in dispersal parameters are reduced by increased sampling effort, larger spatial scale of sampling and lower kurtosis of seed dispersal (Robledo-Arnuncio and García, 2007). Thus, a higher number of well-distributed seed traps in Cuéllar, as well as a higher fecundity, a bigger plot and less leptokurtic curves would explain the better correlation among observed and predicted values in this stand. Given the expected higher accuracy for fitted dispersal curves from Cuéllar, we chose one of the kernels from this site, Cu04, as input for SORTIE simulations.

Apart from sampling issues, differences in functional shape of best-fitting kernels could be due to individually and temporally variable ecological factors such as weather conditions or landscape configuration (Clobert et al., 2012). In our case, the less heterogeneous density in Coca (Cuêllar is characterised by dense areas intermingled with clearings) may have influenced the functional shape of the best-fitting kernel in this population. Increased tree density at the source shortens median dispersal distance while enhancing long-distance dispersal (Schurr et al., 2008).

Most fitted kernels for maritime pine were non- or little leptokurtic. In contrast to our study, several works in temperate trees have found strongly leptokurtic seed dispersal kernels (Nathan et al., 2000; Greene et al., 2004; Jones et al., 2005; Lavi et al., 2005). Accordingly, in the light of our results, maritime pine would probably have a lower capability for LDD than other forest trees.

In this study, traps were located at least $25 \mathrm{~m}$ from the edge of the plot, so immigrant seed rain was assumed to be zero (median dispersal distances estimated for $P$. pinaster of $\sim 14$ to $25 \mathrm{~m}$ ). This assumption is common in modelling techniques to adjust dispersal kernels (Ribbens et al., 1994; Schurr et al., 2008). However, other studies (e.g. Jones and Muller-Landau, 2008) have suggested that curve fits without consideration of immigrant seed rain lead to overestimation of dispersal distances and fecundities. The degree of such overestimation would depend on immigration rates. Clark et al. (1998) proved that excluding potential source trees at the edge of the study area has little effect on estimates for species with short to intermediate dispersal distances $(<25 \mathrm{~m})$, such as is the case in $P$. pinaster, but a substantial effect for species with longer dispersal distances.

\subsection{Insights on maritime pine spread potential}

Our simulation framework showed a noticeable capacity of $P$. pinaster to reach favourable sites for regeneration within its current distribution and to colonise new available territory (as long as the subsequent recruitment process was successful), even considering moderate LDD (in terms of both number and distance travelled, see Clark et al., 2003; Williams et al., 2006).

The potential area invaded by $P$. pinaster is conditioned by the characteristics of the initial stand (size and number of trees; see Fig. 5a). A similar dependence on initial population size and area for forest tree spread has also been shown by Bialozyt et al. (2006). With regards to $P$. pinaster's mating system, fertility turned out to be one of the most influential factors in population spread (see Fig. 5b), as low fertility rates limit the dispersion capacity.

Simulations including LDD events produced much larger invaded areas (up to $\sim 10$-fold) due to the establishment of trees ahead of the main wave of colonisation (see Fig. $5 \mathrm{c}$ ). These trees have critical importance because they work as new seed sources in expanding populations (Lavi et al., 2005). The importance of rare LDD events has also been noted for other forest tree species (Lavi et al., 2005; Nehrbass et al., 2007) or can be deduced from theoretical models (Clark et al., 2003; Hastings et al., 2005; Higgins and Richardson, 1999; Le Corré et al., 1997). LDD events can also make novel niches available for establishment and growth, which could promote local adaptation and niche expansion, and mitigate the impact of the ongoing process of climate change in wide-breadth pine species, such as $P$. pinaster. 


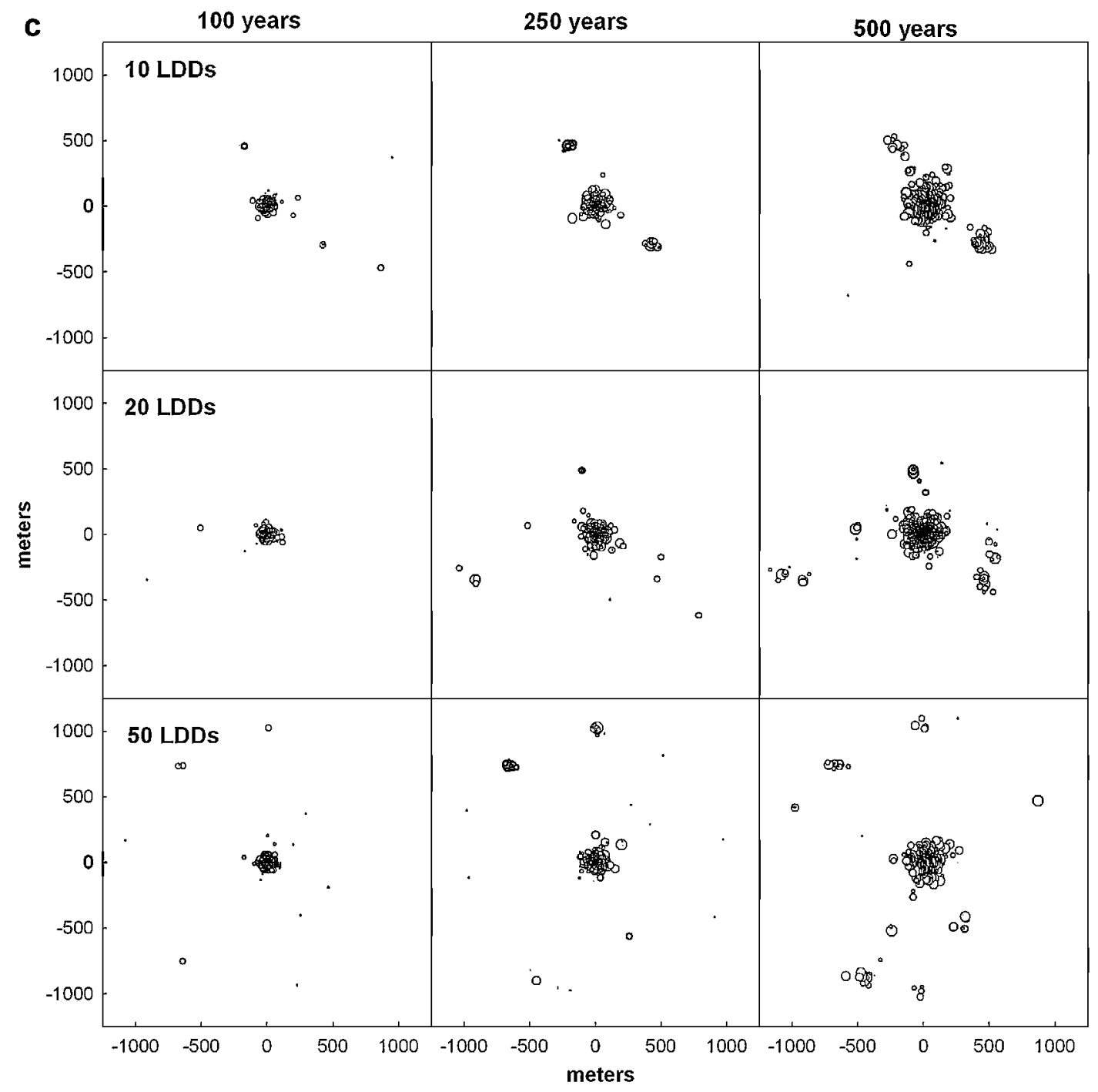

Fig. 5 (continued)

\section{Conclusions}

Maritime pine stands from the Spanish Northern Plateau (central Spain) face increasing difficulties for natural regeneration, which can threaten their future persistence. Shape of dispersal kernels and associated dispersal distances, and the frequency of longdistance dispersal events decisively condition the ability of species to reach safe sites for regeneration and to colonise new areas, especially under the current and near-future climate changes. Our estimates of female fertility, and dispersal distances and spread rates suggest that recruitment in $P$. pinaster is not limited by either the production of seeds or its dispersion capability. In addition, we found great variation in fertility and seed dispersal across stands and years, and even within a year, as well as a high individual variation in female fertility. Likewise, the best-fitting dispersal kernels were different for each stand, with Cuéllar following the lognormal model and Coca the 2Dt model. These findings highlight the high stochasticity of the regeneration process in Mediterranean environments. Spread rates estimated in maritime pine were low ( $\sim 1.1 \mathrm{~m} /$ year). Nevertheless, they appear sufficient to colonise abandoned crop land in the region, expanding its current range, in particular under increased fertility and frequent long-distance dispersal scenarios.

\section{Acknowledgements}

We are grateful to Ricardo Alía, Fernando del Caño, Isidoro Miguel-Pérez and Castilla y Léon's Regional Forest Service for help in establishing the experimental sites. Thanks are extended to the anonymous reviewer for the valuable comments and suggestions to improve the quality of the paper and to P.C. Grant who revised the English language. This work was funded by grants from the Spanish Ministries of Science and Innovation (Project AGL200507440-C02-01/FOR and AGL2007-65795-C02-01), and Environment (Contracts CC03-048 and AEG06-054).

\section{References}

Bialozyt, R., Ziegenhagen, B., Petit, R.J., 2006. Contrasting effects of long distance seed dispersal on genetic diversity during range expansion. Journal of Evolutionary Biology 19, 12-20.

Calama, R. Gordo, F.J., Mutke, S., Montero, G., 2008. An empirical ecological-type model for predicting stone pine (Pinus pinea $\mathrm{L}$.) cone production in the Northern Plateau (Spain). Forest Ecology and Management 255, 660-673.

Calama, R., Mutke, S., Tomé, J., Gordo, J., Montero, G., Torné, M., 2011. Modelling spatial and temporal variability in a zero-inflated variable: the case of stone pine (Pinus pinea L.) cone production. Ecological Modelling 222, 606-618. 
Clark, J.S., Macklin, E., Wood, L., 1998. Stages and spatial scales of recruitment limitation in southern Appalachian forests. Ecological Monographs 68, 213-235.

Clark, J.S., Silman, M., Kern, R., Macklin, E., HilleRisLambers, J., 1999. Seed dispersal near and far: patterns across temperate and tropical forests. Ecology 80, 14751494.

Clark, J.S., Lewis, M., Mclachlan, J.S., HilleRisLambers, J., 2003. Estimating population spread: what can we forecast and how well? Ecology 84, 19791988

Clobert, J., Baguette, M., Benton, T., Bullock, J.M., 2012. Dispersal Ecology and Evolution. Oxford University Press (462pp.).

Coates, K.D., Canham, C.D., Beaudet, M., Sachs, D.L., Messier, C., 2003. Use of a spatially explicit individual-tree model (SORTIE/BC) to explore the implications of patchiness in structurally complex forests. Forest Ecology and Management $186,297-310$.

Dovčiak, M., Hrivnák, R., Ujházy, K., Gömöry, D., 2008. Seed rain and environmental controls on invasion of Picea abies into grassland. Plant Ecology 194, 135-148.

Garcia, C., Jordano, P., Godoy, A., 2007. Contemporary pollen and seed dispersal in a Prunus mahaleb population: patterns in distance and direction. Molecular Ecology 16, 1947-1955.

González-Alday, J., Martínez-Ruíz, C., Bravo, F., 2009. Evaluating different Harvest intensities over understory plant Diversity and pine seedling in a Pimus pinaster Ait. natural stand of Spain. Plant Ecology 201, 211-220.

González-Martínez, S.C., Burczyk, J., Nathan, R., Nanos, N., Gìl, L., Alía, R., 2006 Effective gene dispersal and female reproductive success in Mediterranean maritime pine (Pinus pinaster Aiton). Molecular Ecology 15, 4577-4588.

Gordo, J. Calama, R., Pardos, M., Bravo, F., Montero, G., (Eds). 2012. La regeneración natural de los pinares en los arenales de la Meseta Castellana. Instituto Universitario de Investigación en Gestión Forestal Sostenible (Universidad de Valladolid-INIA). Valladolid. $254 \mathrm{pp}$.

Grace, S.L., Hamrick, J.L., Platt, W.J., 2004. Estimation of seed dispersal in an oldgrowth population of longleaf pine (Pimus palustris) using maternity exclusion analysis. Castanea 69, 207-215.

Greene, D.F., Johnson, E.A., 1989. A model of wind dispersal of winged or plumed seeds. Ecology 70, 339-347.

Greene, D.F., Canham, C.D., Coates, K.D., Lepage, P.T., 2004. An evaluation of alternative dispersal functions for trees. Journal of Ecology 92, 758-766.

Guarigata, M.R., Pinard, M.A., 1998. Ecological knowledge of regeneration from seed in neotropical forest trees: implications for natural forest management. Forest Ecology and Management 112, 87-99.

Hastings, A Cuddington, K, Davies, K.D., Dugaw, C. Elmendorf, S., Freestone, A Harrison, S., Holland, M., Lambrinos, J., Malvadkar, U., Melbourne, B.A., Moore, K., Taylor, C., Thomson, D., 2005. The spatial spread of invasions: new developments in theory and evidence. Ecology Letters 8, 91-101.

Higgins, S.I., Richardson, D.M., 1999. Predicting plant migration rates in a changing world: the role of long-distance dispersal. American Naturalist 153, 464-475.

Higgins, S.I., Richardson, D.M., Cowling, R.M., 2001. Validation of a spatia simulation model of a spreading alien plant population. Journal of Applied Ecology 38 (3), 571-584

Higgins, S.I., Clark, J.S., Nathan, R., Hovestadt, T., Schurr, F.M., Fragoso, J.M.V., Aguiar, M.R., Ribbens, E., Lavorel, S., 2003. Forecasting plant migration rates: managing uncertainty for risk assessment. Journal of Ecology 91, 341-347.

Houle, G., 1996. Environmental filters and seedling recruitment on a coastal dune in subarctic Quebec (Canada). Canadian Journal of Botany 74, 1507-1513.

Jones, F.A. Muller-Landau, H.C., 2008. Measuring long-distance seed dispersal in complex natural environments: an evaluation and integration of classical and genetic methods. Journal of Ecology 96, 642-652.

Jones, F.A., Chen, J., Weng, G.J., Hubbell, S.P., 2005. A genetic evaluation of seed dispersal in the Neotropical tree Jacaranda copaia (Bignoniaceae). American Naturalist $166,543-555$.

Kitajima, K., Fenner, M., 2000. Ecology of seedling regeneration. In: Fenner, M. (Ed.), Seeds: The Ecology of Regeneration in Plant Communities. CAB International, Wallingford, UK

Kremer, A., Ronce, O., Robledo-Arnuncio, J.J., Guillaume, F., Bohrer, G., Nathan, R. et al., 2012. Long-distance gene flow and adaptation of forest trees to rapid climate change. Ecology letters 15, 378-392.

Lavi, A., Perevolotsky, A., Kigel, J., Noy-Meir, I., 2005. Invasion of Pinus halepensis from plantations into adjacent natural habitats. Applied Vegetation Science $8,85-92$

Le Corré, V., Machon, N., Petit, R.J., Kremer, A., 1997. Colonization with long-distance seed dispersal and genetic structure of maternally inherited genes in forest trees: a simulation study. Genetic Resources 69, 117-125.

Lowe, S., Browne, M., Boudjelas, S., de Poorler, M., 2004. 100 de las especies exóticas más dañinas del mundo. Una selección del Global Invasive Species Database. Grupo Especialista de Especies Invasoras (GEEI), Auckland, Nueva Zelanda.

Manso, R., Pardos, M., Keyes, C.R., Calama, R., 2012. Modelling the spatio-temporal pattern of primary dispersal in stone pine (Pinus pinea $\mathrm{L}$.) stands in the Northern Plateau (Spain). Ecological Modelling 226, 11-21.

Merlo, E., Fernández-López, J., 2004. Análisis del balance parental reproductivo en un huerto semillero de Pinus pinaster Ait. Investigación Agraria: Sistemas y Recursos Forestales 13, 387-398.
Miguel-Pérez, I., González-Martínez, S.C., Alía, R., Gil, L., 2002. Growth phenology and mating system of maritime pine (Pinus pinaster Aiton) in central Spain. Investigación Agraria: Sistemas y Recursos Forestales 11, 193-204.

Murphy, L.E., 2008. SORTIE-ND user manual, Version 6.09. Millbrook, New York.

Mutke, S., Gordo, J., Gil, L., 2005. Variability of Mediterranean Stone pine cone production: yield loss as response to climate change. Agricultural and Forest Meteorology 132, 263-272.

Nanos, N., Larson, K., Milleron, M., Sjöstedt-de Luna, S., 2010. Inverse modelling for effective dispersal: do we need tree size to estimate fecundity? Ecological Modelling 221, 2415-2424.

Nathan, R., 2001. The challenges of studying dispersal. Trends in Ecology and Evolution 16, 481-483.

Nathan, R., Muller-Landau, H.C., 2000. Spatial patterns of seed dispersal, their determinants and consequences for recruitment. Trends in Ecology and Evolution 15, 278-285.

Nathan, R., Safriel, U.N., Noy-Meir, I., Schiller, G., 1999. Seed release without fire in Pinus halepensis, a Mediterranean serotinous wind-dispersed tree. Journal of Ecology 87, 659-669.

Nathan, R., Safriel, U.N., Noy-Meir, I., Schiller, G., 2000. Spatiotemporal variation in seed dispersal and recruitment near and far from Pinus halepensis trees. Ecology $81,2156-2169$.

Nathan, R., Safriel, U.N., Noy-Meir, I., 2001. Field validation and sensitivity analysis of a mechanistic model for tree seed dispersal by wind. Ecology 82 (2), 374-388.

Nathan, R., Katul, G.G., Horn, H.S., Thomas, S.M., Oren, R., Avissar, R., Pacala, S.W., Levin, S.A., 2002. Mechanisms of long-distance dispersal of seeds by wind Nature 418, 409-413.

Nathan, R., Schurr, F.M., Spiegel, O., Steinitz, O., Trakhtenbrot, A., Tsoar, A., 2008. Mechanisms of long-distance seed dispersal. Trends in Ecology and Evolution 23 (11), 638-647.

Nehrbass, N., Winkler, E., Müllerovâ, J., Pergl, J., Pyšek, P., Perglovâ, I., 2007. A simulation model of plant invasion: long-distance dispersal determines the pattern of spread. Biological Invasions 9, 383-395.

Ouborg, N.J., Piquot, Y., Van Groenendael, J.M., 1999. Population genetics, molecular markers and the study of dispersal in plants. Journal of Ecology 87, 551-568.

Pacala, S.W., Canham, C.D., Silander Jr., J.A., 1993. Forest models defined by field measurements. 1. The design of a northeastern forest simulator. Canadian Journal of Forest Research 23, 1980-1988.

Pedersen, S.M., 2007. Models of individual tree mortality for trembling aspen, lodgepole pine, hybrid spruce and subalpine fir in northwestern British Columbia. PhD dissertation, Dept. of Forest Ecology and Management, SLU, Sweden.

Prévosto, B., Hill, D.R.C., Coquillard, P., 2003. Individual-based modelling of Pimus sylvestris invasion after grazing abandonment in the French Massif Central. Plant Ecology 168, 121-137.

Ribbens, E., Silander Jr., J.A., Pacala, S.W., 1994. Seedling recruitment in forests: calibrating models to predict patterns of tree seedling dispersion. Ecology 75 , $1794-1806$.

Robledo-Arnuncio, J.J., García, C., 2007. Estimation of the seed dispersal kernel from exact identification of source plants. Molecular Ecology 16, 5098-5109.

Rodríguez-García, E., Juez, L., Bravo, F., 2010. Environmental influences on postharvest natural regeneration of Pinus pinaster Ait. in Mediterranean forest stands submitted to the seed-tree selection method. European Journal of Forest Research 129, 1119-1128.

Rodriguez-Garcia, E., Gratzer, G., Bravo, F, 2011. Climatic variability and other site factor influences on natural regeneration of Pinus pinaster Ait. in Mediterranean forests. Annals of Forest Science 68, 811-823.

Ruano, I., Pando, V., Bravo, F., 2009. How do light and summer rainfall influence Pinus pinaster Ait. germination and early seedling development? Forest Ecology and Management 258 (12), 2647-2653.

Sagnard, F., Pichort, C., Dreyfus, P., Jordano, P., Fady, B., 2007. Modelling seed dispersal to predict seedling recruitment: recolonization dynamics in a plantation forest. Ecological Modelling 203, 464-474.

Schupp, E.W., Fuentes, M., 1995. Spatial patterns of seed dispersal and the unification of plant population ecology. Ecoscience 2, 267-275.

Schurr, F.M., Steinitz, O., Nathan, R., 2008. Plant fecundity and seed dispersal in spatially heterogeneous environments: models, mechanisms and estimation. Journal of Ecology $96,628-641$.

Serrada, R., González, G.M., Reque, J.A., 2008. Compendio de selvicultura aplicada en España. Instituto Nacional de Investigación. Madrid, Spain. 1178 pp.

Thuiller, W., Lavorel, S., Araújo, M.B., Sykes, M.T., Prentice, I.C., 2005. Climate change threats to plant diversity in Europe. Proceedings of the National Academy of Sciences of USA $102,8245-8250$

Tíscar Oliver, P.A., 2007. Dinámica de regeneración de Pinus nigra subsp. Salzmannii al sur de su área de distribución: etapas, procesos y factores implicados. Investigación Agraria: Sistemas y Recursos Forestales 16 (2) 124-135.

Williams, C.G., LaDeau, S.L., Oren, R., Katul, G.G., 2006. Modelling seed dispersal distances: implications for transgenic Pimus taeda. Ecological Applications 16, 117-124. 